\title{
Duane's syndrome and familial perceptive deafness
}

\author{
T. H. KIRKHAM
}

Sheffield Royal Infirmary

This communication reports the occurrence of two cases of Duane's retraction syndrome in a family affected through five generations with dominantly inherited perceptive deafness (Fig. I). The significance of this finding is discussed.

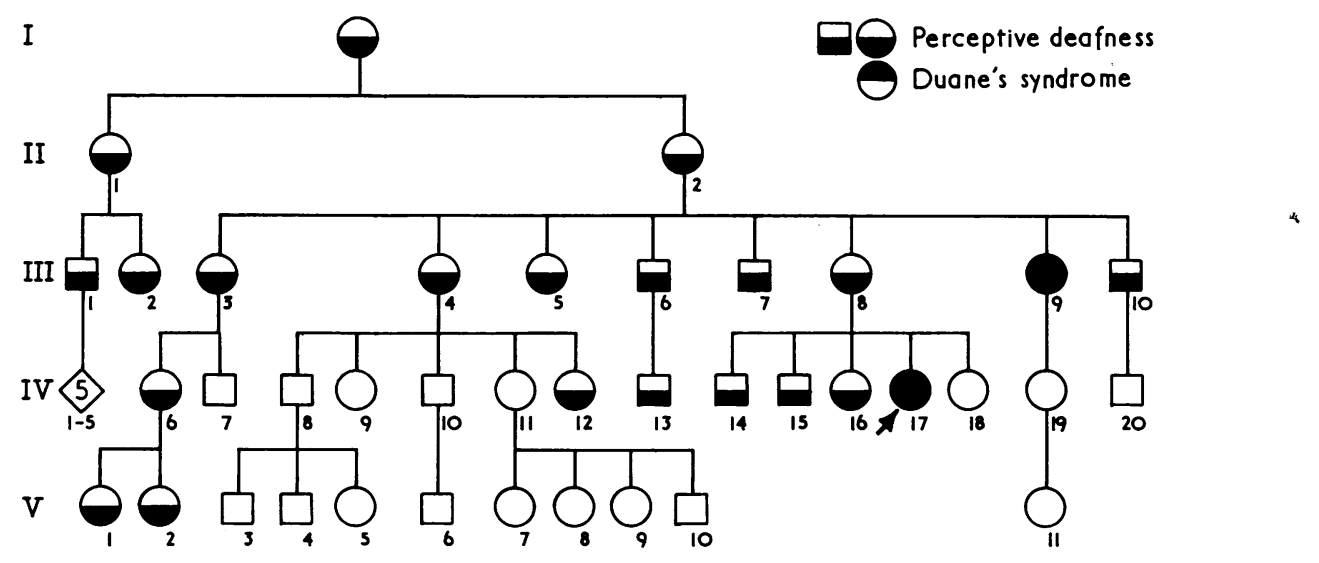

FIG. I Family pedigree

\section{Case IV 17}

A 15-year-old girl, who had a left-sided Duane's syndrome, was noted to be profoundly deaf with a severe speech defect. The deafness had been detected at the age of 5 years and necessitated her attendance at a special school. A slight facial asymmetry was present and she adopted an abnormal head posture, turning the head to the left side. Some degree of mental retardation was present but no other general physical abnormalities were detected. A urinary amino acid chromatogram did not show any abnormalities.

\section{Ocular examination}

The visual acuity was $6 / 5$, with $+3 \mathrm{D}$ sph., in the right eye, and $6 / 6$, with $+4.5 \mathrm{D} \mathrm{sph}$., $+0.5 \mathrm{D}$ cyl., axis $90^{\circ}$, in the left.

The movements of the right eye were normal. In the primary position slight left ptosis was present. The cover test revealed esophoria while adopting the abnormal head posture. On adduction of the left eye, which was slightly restricted, marked retraction of the globe and narrowing of the palpebral fissure occurred. Widening of the palpebral fissure occurred on attempted abduc- 


\section{6}

tion which was severely limited. The Hess chart shows the limited action of the left lateral rectus and the marked overaction of the right medial rectus (Fig. 2).
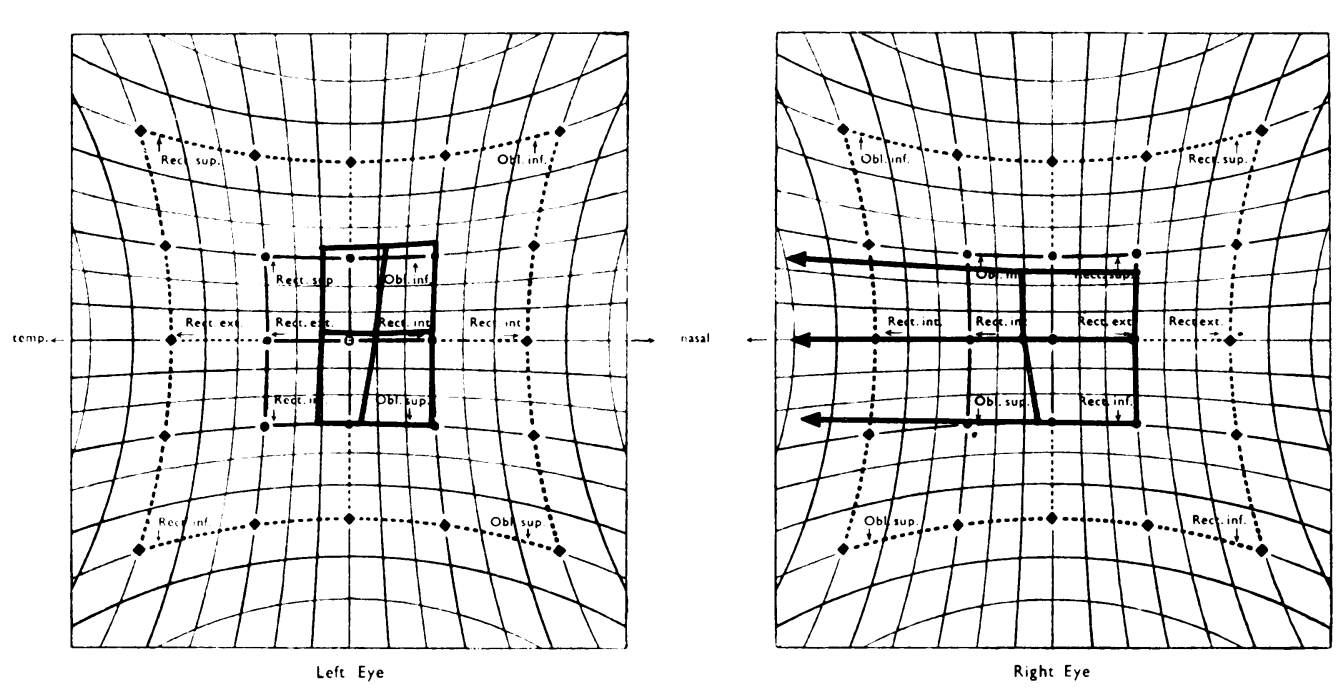

Fig. 2 Hess chart of Ciase IV I 7

No ocular defects were present other than the disturbance of oculomotor function and the aniso metropia.

\section{Otolaryngological examination}

The palate, throat, pinnae and tympanic membranes were normal. A pure tone audiogran demonstrated a severe degree of perceptive deafness (Fig. 3).

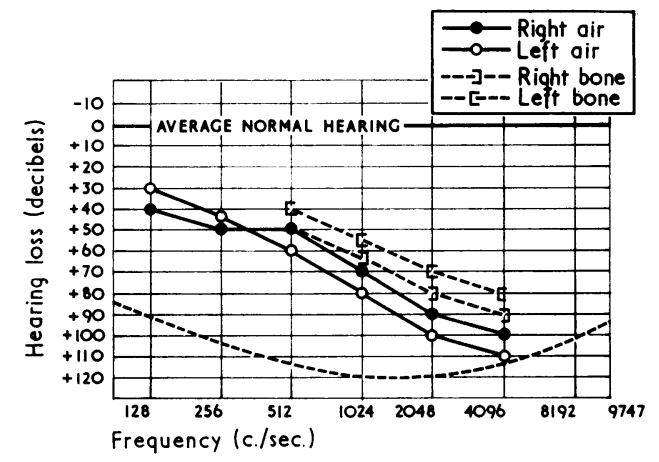

FIG. 3 Audiogram of Case IV I 7 , showing severie perceptive deafness

At a routine refraction visit the child was accompanied by her mother who was alsô observed to be deaf. Investigation of the family led to the discovery of Case III 9 who alsष has a left-sided Duane's syndrome.

\section{Case III 9}

A 47-year-old woman had always known her left eye to be "weak" but had never sought a市 ophthalmic opinion. She was severely deaf although her speech was only moderately impaire $\frac{0}{8}$ Her deafness had become manifest at about the age of 15 years. No general physical abnormalitie were present. She habitually turned her head to the right side. 


\section{Ocular examination}

The visual acuity was $6 / 5$, with $+0.5 \mathrm{D}$ sph., in the right eye, and $6 / 36$, with $+2 \cdot 25 \mathrm{D}$ sph., $+2 \mathrm{D}$ cyl., axis $80^{\circ}$, in the left.

Visuscope examination showed central fixation with either eye. No fundus abnormality was present. The movements of the right eye were normal. Exophoria was present when she adopted the abnormal head posture. Marked retraction of the left globe and narrowing of the palpebral fissure occurred on attempted adduction, which was severely limited, and widening of the palpebral fissure occurred on attempted abduction which was also deficient. The Hess chart (Fig. 4) clearly shows that adduction of the left eye is more limited than abduction in this case.
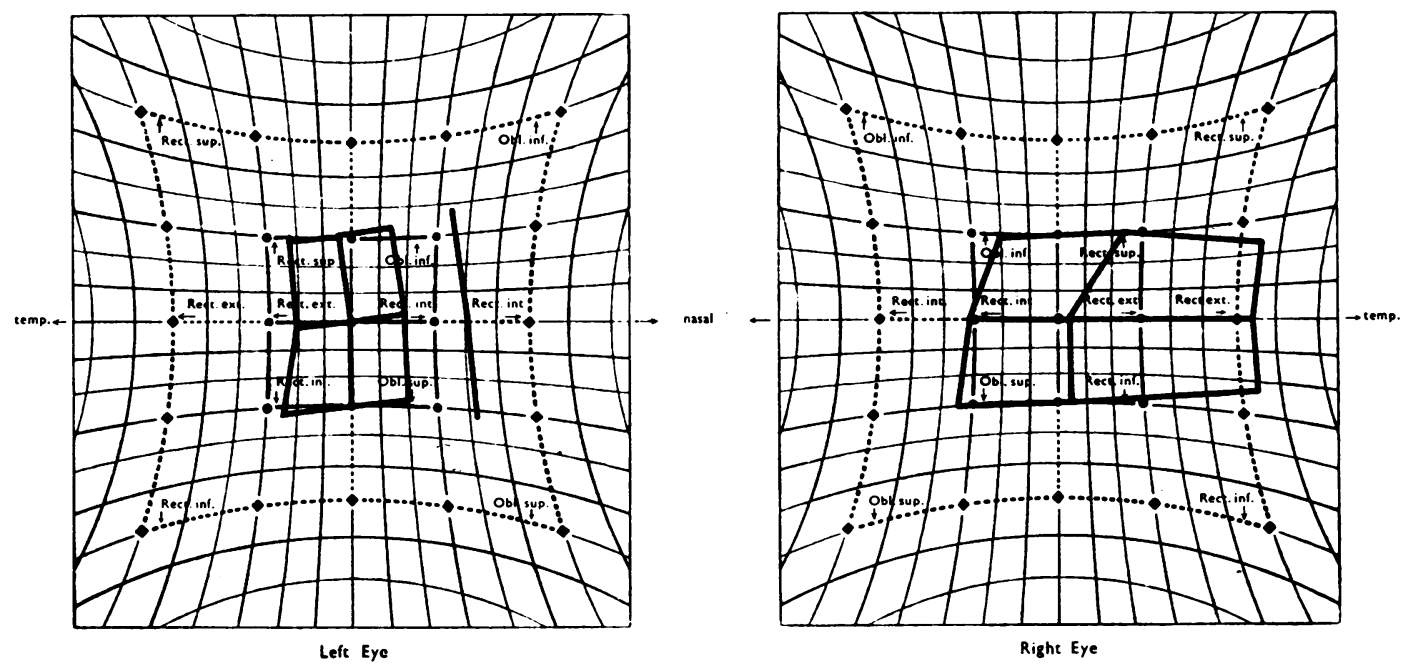

FIG. 4 Hess chart of Case III 9

\section{Otolaryngological examination}

Palate, pinnae, and tympanic membranes were normal. Pure tone audiography showed a severe degree of perceptive deafness (Fig. 5).

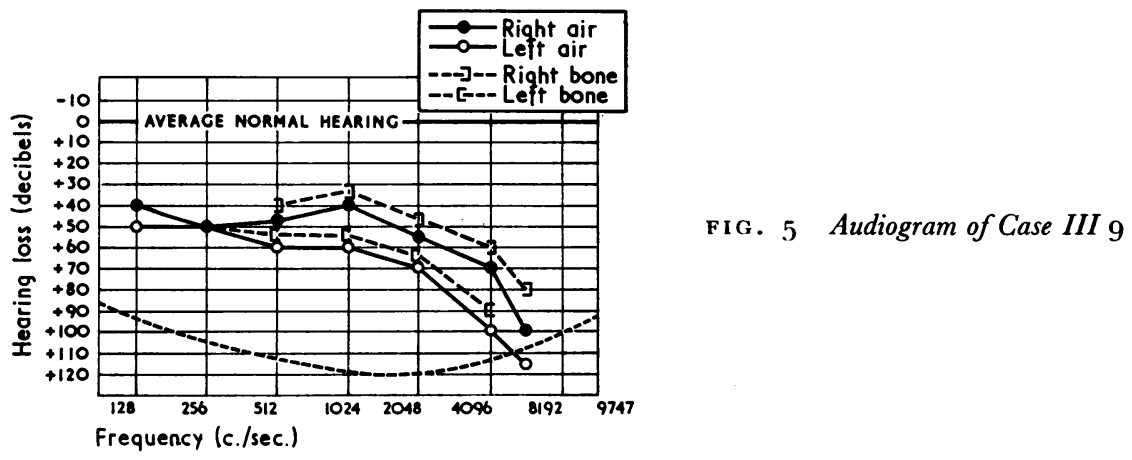

In the remaining family members who were examined no other cases demonstrating abnormal ocular movements were discovered. Some had anisometropia but without amblyopia. In many cases perceptive deafness was present which, in the majority, had become manifest at the age of puberty. In others the deafness occurred in early childhood 
and led to a severe degree of speech defect necessitating special school education (Case IV I 7, V I, and V 2). No member of the family had any clinical abnormality of the cervical spine. It was not possible to trace the descendents of Cases III I and III both of whom were clearly remembered by Ciase III 5 to be "deaf mutes".

\section{Discussion}

Marked limitation of abduction of the globe and widening of the palpebral fissure of attempts at abduction, with less marked limitation of adduction and retraction of the globe with narrowing of the palpebral aperture on attempts at adduction were described by Duane (1905) as the retraction syndrome. In addition, there is often an upshoot or downshoot of the affected eye on attempted adduction. Case IV I 7 is an example this classical description. Her aunt, Case III 9, however, shows more limitation adduction than abduction and has, therefore, adopted a compensatory head posture consisting of a head turn to the unaffected side. Lyle and Bridgeman (1959) have subiv divided cases of Duane's syndrome on the basis of the degree of limitation of adduction of abduction. That an exodeviation is by no means uncommon was shown by Mein ( 968 ₹ in her study of 77 cases of Duane's syndrome, in which 62 cases had an exodeviation in the primary position. Danis (1948) collected 227 cases of Duane's syndrome from the literature, adding two more personally observed cases. Deafness was not mentioned aso an associated feature in any of these cases. Since then, many further cases have beero added to the literature and in the majority of reports the presence or absence of deafnes: is not mentioned.

It was not until the isolated reports of Wildervanck (1952), Waardenburg (1953), an⿳亠ेष Franceschetti and Klein (1 954) of cases showing Duane's syndrome, deafness, and abnoro malities of the cervical spine were collected by Wildervanck (1960) along with othe similar cases under the title of "cervico-oculo-acusticus syndrome" that the existence of relationship between these conditions was realised. Windervanck, Hoeksema, and Penning ( 1966 ) stated that they knew of $5^{1}$ such cases and that, as in the case of many syndromeso one of the features may be absent. In the cases they described the deafness was congenitat. and of profound degree. No definite hereditary tendency has so far been established: although they found occasional deafness in the relatives of some of their cases. Pintucc? and di Tizio ( 196 I) described a young man with Duane's syndrome and the Klippel-Feiß anomaly but with normal hearing, in whose family an isolated case of Duane's syndrome occurred.

In the present family the deafness is of a dominant heredo-degenerative character? usually becoming manifest at puberty. In a few family members the deafness was manifes in early life and led to the development of a severe speech defect. The variation in age af onset between different family members probably indicates varying expressivity of th尺 genetic factor responsible for the deafness.

This is the first time that the occurrence of two cases of Duane's syndrome with perceptive deafness in one family has been reported and the first time that the genetic character of the deafness has been clearly defined.

It seems probable that, in view of the finding of this association and of the previouslyc reported isolated cases mentioned above, there is a definite genetic relationship betweer some cases of Duane's syndrome and perceptive deafness. One has seen several othe $\frac{?}{\mathrm{D}}$ instances of Duane's syndrome accompanied by perceptive deafness which strengtheng this belief (Kirkham, unpublished data). 
Fraser (1964) regarded profound deafness in childhood as a socio-educational problem and deprecated the use of the term deaf-mutism which implies a defect in the speech mechanism which is not, in fact, present.

Future reported instances of Duane's syndrome should include a family history and cases should be examined for the presence of perceptive deafness which might necessitate special education.

\section{Summary}

Two patients with Duane's syndrome, who were themselves deaf, were found in a family affected through five generations with perceptive deafness. This is the first report of two such cases within the same family. This discovery strengthens the belief that there is a genetic relationship between Duane's syndrome and perceptive deafness, since such an association has been previously recorded in isolated cases.

Investigation of patients with Duane's syndrome should include a family history and an audiological examination.

I wish to thank Mr. A. Stanworth for permission to examine and report on Case IV 17. My thanks are also extended to Dr. D. Kilby for the otolaryngological examinations.

\section{References}

DANis, P. (1948) Ann. Oculist. (Paris), 181, 148

DUANE, A. (1905) Arch. Ophthal. (N.Y.), 34, 133

FRANCESCHETTI, A., and KLEIN, D. (1954) J. Génét. hum., 3, I 76

FRASER, G. R. (1964) F. med. Genet., I, 1 i 8

LYLE, T. K., and BRIDGeman, G. J. O. (1959) "Worth and Chavasse's Squint", 9th edition, p. 25 I.

Baillière, Tindall and Cox, London

MEIN, J. (I968) In "Transactions of the First International Congress of Orthoptists, London, I967",

p. 165 . Kimpton, London

PINTUCCI, F., and DI TIZIO, A. (196i) 7. Génét. hum., 10, I56

waArdenburg, P. J. (1953) v. Graefes Arch. Ophthal., 154, 96

WiLdervanck, L. s. (1952) Ned. T. Geneesk., 96, 2752

(1960) Ibid., 104, 2600

- hOeksema, P. E., and PENNing, L. (1966) Acta oto-laryng. (Stockh.), 6r, 445 